\title{
Alcohol and mortality after moderate to severe traumatic brain injury: a meta-analysis of observational studies
}

\author{
${ }^{*}$ Rahul Raj, MD, PhD, ${ }^{1}$ Era D. Mikkonen, MD, ${ }^{2}$ Jari Siironen, MD, PhD, ${ }^{1}$ Juha Hernesniemi, MD, PhD, ${ }^{1}$ \\ Jaakko Lappalainen, MD, PhD, ${ }^{1}$ and Markus B. Skrifvars, MD, PhD, EDIC, FCICM ${ }^{2}$
}

Departments of ${ }^{1}$ Neurosurgery and ${ }^{2}$ Intensive Care, Helsinki University Hospital, Helsinki, Finland

OBJECTIVE Experimental studies have shown numerous neuroprotective properties of alcohol ("ethanol") after TBI, but clinical studies have provided conflicting results. The authors aimed to assess the relationship between positive blood alcohol concentration (BAC) on hospital admission and mortality after moderate to severe traumatic brain injury (TBI).

METHODS The authors searched 8 databases for observational studies reported between January 1, 1990, and October 7, 2013, and investigated the effect of BAC on mortality after moderate to severe TBI. Reviews of each study were conducted, and data were extracted according to the MOOSE and PRISMA guidelines. Study quality was assessed using the Newcastle-Ottawa scale. The Mantel-Haenszel fixed effect methodology was used to generate pooled estimates. Heterogeneity was dealt with by multiple sensitivity analyses.

RESULTS Eleven studies with a total of 95,941 patients (42\% BAC positive and $58 \%$ BAC negative) were identified for the primary analysis (overall mortality $12 \%$ ). Primary analysis showed a significantly lower risk of death for BAC-positive patients compared with BAC-negative patients (crude mortality $11.0 \%$ vs $12.3 \%$, pooled OR 0.84 [95\% Cl $0.81-0.88]$ ), although flawed by heterogeneity $\left(1^{2}=68 \%\right)$. Multiple sensitivity analyses, including 55,949 and 51,772 patients, yielded similar results to the primary analysis (crude mortality $12.2 \%$ vs $14.0 \%$, pooled OR 0.87 [ $95 \% \mathrm{Cl} 0.83-0.92]$ and crude mortality $8.7 \%$ vs $10.7 \%$, pooled OR $0.78[95 \% \mathrm{Cl} 0.74-0.83]$ ) but with good study homogeneity ( ${ }^{2}=36 \%$ and $14 \%$ ).

CONCLUSIONS Positive BAC was significantly associated with lower mortality rates in moderate to severe TBI. Whether this observation is due to selection bias or neuroprotective effects of alcohol remains unknown. Future prospective studies adjusting for TBI heterogeneity is advocated to establish the potential favorable effects of alcohol on outcome after TBI.

http://thejns.org/doi/abs/10.3171/2015.4.JNS141746

KEY WORDS traumatic brain injury; alcohol; ethanol; mortality; outcome; prognosis; intoxication; trauma

$\mathrm{T}$ Raumatic brain injury (TBI) is defined as an alteration of brain function, or other evidence of brain pathology, caused by an external force. ${ }^{28}$ Moderate to severe TBI is a major cause of mortality and morbidity in the world..$^{27}$ Every year approximately 1.5 million people die and 10 million people are hospitalized due to TBI. ${ }^{18}$ This leads to great suffering for patients and their relatives, with huge direct and indirect costs to society. ${ }^{10,32}$ It has been estimated that the annual costs of TBI in the US are more than $\$ 76.5$ billion. ${ }^{9}$ Numerous clinical trials have failed to demonstrate the efficacy of promising experimental neuroprotective agents despite convincing preclinical data. Over the past 2 decades there have not been clear improvements in the prognosis of patients with TBI. ${ }^{24,25}$

\section{Description of the Intervention}

Up to half of all patients with TBI are under the influence of alcohol at the time of injury. ${ }^{44,49}$ Clinical studies investigating the role of alcohol (ethanol, $\mathrm{CH}_{3} \mathrm{CH}_{2} \mathrm{OH}$, referred to as alcohol in the present study) on the outcome of TBI have been either retrospective or observational, as it probably would be unethical, unless strong evidence can be laid out, to administer alcohol to patients presenting with TBI. This meta-analysis investigates the impact of the presence of blood alcohol concentration (BAC) on outcome after TBI.

\section{How Might Alcohol Work as a Neuroprotective Agent?}

The neuroprotective properties of alcohol have been

ABBREVIATIONS AIS = Abbreviated Injury Scale; BAC = blood alcohol concentration; GCS = Glasgow Coma Scale; NMDAR = N-methyl-D-aspartate receptor; TBI = traumatic brain injury.

SUBMITTED July 29, 2014. ACCEPTED April 28, 2015.

INCLUDE WHEN CITING Published online October 23, 2015; DOI: 10.3171/2015.4.JNS141746.

* Drs. Raj and Mikkonen contributed equally to this work. 
established in preclinical models. ${ }^{17,33}$ These effects seem to be strongest at low to moderate levels of BAC (approximately $1.0 \%$ ).

Several hypotheses have been developed as to what might explain the neuroprotective properties of alcohol. These hypotheses include inhibition of $N$-methyl-D-aspartate receptor (NMDAR) excitoxicity, improved cerebral coupling, reduced systemic and cerebral inflammatory response, reduced hyperthermia, and blunting of hyperadrenergic surge. . $^{17,33}$

TBI causes an excessive release of the neurotransmitter glutamate, which leads to excitotoxicity, a phenomenon strongly associated with neuronal death. ${ }^{19}$ The neuroprotective effects of alcohol have been mainly attributed to its NMDAR-blunting effects. ${ }^{17}$ On the other hand, following brain injury, the NMDAR activation becomes crucial for neuronal survival, which may explain why NMDARblocking agents have failed in clinical trials., ${ }^{5,15}$

Trauma in general is followed by a catecholamine surge due to sympathetic activation, and a prolonged hyperadrenergic state, which may impair the outcome of TBI patients. ${ }^{8,11}$ It has been shown that alcohol administration can blunt this surge and possibly improve outcome in patients with TBI. ${ }^{52}$ However, high BAC (exceeding 2.0\%), appears to be associated with impaired outcome. ${ }^{17,54-56}$ This may be due to hemodynamic and respiratory depression, hemostatic derangements, blood-brain barrier dysfunction, and an impaired physiological ability to compensate for shock. ${ }^{17,29}$ Furthermore, it is well established that alcoholintoxicated patients are more susceptible to TBI. The benefit of alcohol administration in TBI seems to be limited to acute intoxication, whereas chronic alcohol use can be associated with upregulation of NMDAR activity and downregulation of GABA-receptor, which could contribute to worse outcome. ${ }^{17}$

\section{Why It Is Important To Conduct This Review}

Numerous clinical trials testing the efficacy of novel pharmaceutical agents in TBI have failed in spite of promising preclinical studies. ${ }^{23,26}$ Alcohol has been shown to have neuroprotective properties both in the experimental setting and in observational studies. However, the lack of clinical trials is evident. Alcohol intoxication is a major global health problem and thus offering alcohol to patients would be controversial, unless robust observational evidence can be laid out.

The objective of this paper was to assess the effect of $\mathrm{BAC}$ on hospital mortality after moderate to severe TBI.

\section{Methods}

This meta-analysis was performed in concordance with the PRISMA (Preferred Reporting Items for Systematic reviews and Meta-analyses) statement and in concordance with the MOOSE (Meta-analysis Of Observational Studies in Epidemiology) guidelines. ${ }^{20,43}$ The checklist of the MOOSE is found in the Supplemental Information.

\section{Literature Search}

We searched PubMed, MEDLINE, PreMEDLINE,
EBM (Evidence Based Medicine) Reviews, Cochrane Database of Systematic Reviews, Cancerlit, CINADH, and EMBASE for studies reported between January 1, 1990, and October 7,2013. A search strategy designed to detect the widest range of studies was made combining different MeSH headings for "traumatic brain injury" and "alcohol/ ethanol" (see Supplemental Information). Only studies in humans and those published in the English language were considered. The literature search was performed by 2 authors independently (R.R. and E.D.M.). A flowchart of the literature search process is shown in Fig. 1.

\section{Study Inclusion and Exclusion Criteria and Missing Data}

Only studies with a primary or secondary aim dedicated to investigating the effect of BAC on mortality after moderate to severe TBI (defined as Glasgow Coma Scale [GCS] score $\leq 12$ and/or head abbreviated injury scale [AIS] score $\geq 3$ ) were considered. Patients of all ages were considered. Both blunt and penetrating TBI injury types were included, as well as both isolated TBI and polytrauma with TBI.

Studies not designed specifically to investigate the effect of BAC on mortality were excluded. Studies not differentiating between non-TBI (i.e., general trauma) and TBI, or differentiating between mild and moderate to severe TBI were excluded. Studies reporting BAC levels in postmortem TBI patients were not considered. The studies that did not incorporate a comparator group (BAC negative) were excluded from the review.

We contacted the study authors when data were missing. If data remained unavailable, the studies were omitted from the analysis.

\section{Outcome}

Hospital mortality was the primary outcome. When hospital mortality was not reported, the closest relevant mortality measure was used.

\section{Quality Scoring}

The Newcastle-Ottawa Scale was used to assess the quality of the studies, as they were all nonrandomized. ${ }^{51}$ This was done by assessing patient selection criteria, compatibility of the BAC-positive and -negative groups and of the outcome in the individual studies. A star rating of 0 to 9 was allocated to each study based on these parameters. The quality assessment was performed by 2 authors independently (R.R. and E.D.M.). When discrepancies arose, papers were reexamined, and consensus was reached by verbal discussion. Studies receiving 6 or more stars are considered high quality.

\section{Statistical Analysis}

For the statistical analyses, Review Manager (RevMan) Computer program version 5.2. Copenhagen: The Nordic Cochrane Centre, The Cochrane Collaboration, 2012 was used. Heterogeneity was assessed by the $\mathrm{I}^{2}(>50 \%$ considered substantial heterogeneity). ${ }^{12,13}$ Heterogeneity in meta-analysis refers to the variation in outcomes between studies. Heterogeneity was dealt with by sensitivity analysis, omitting one study at a time to detect interstudy 


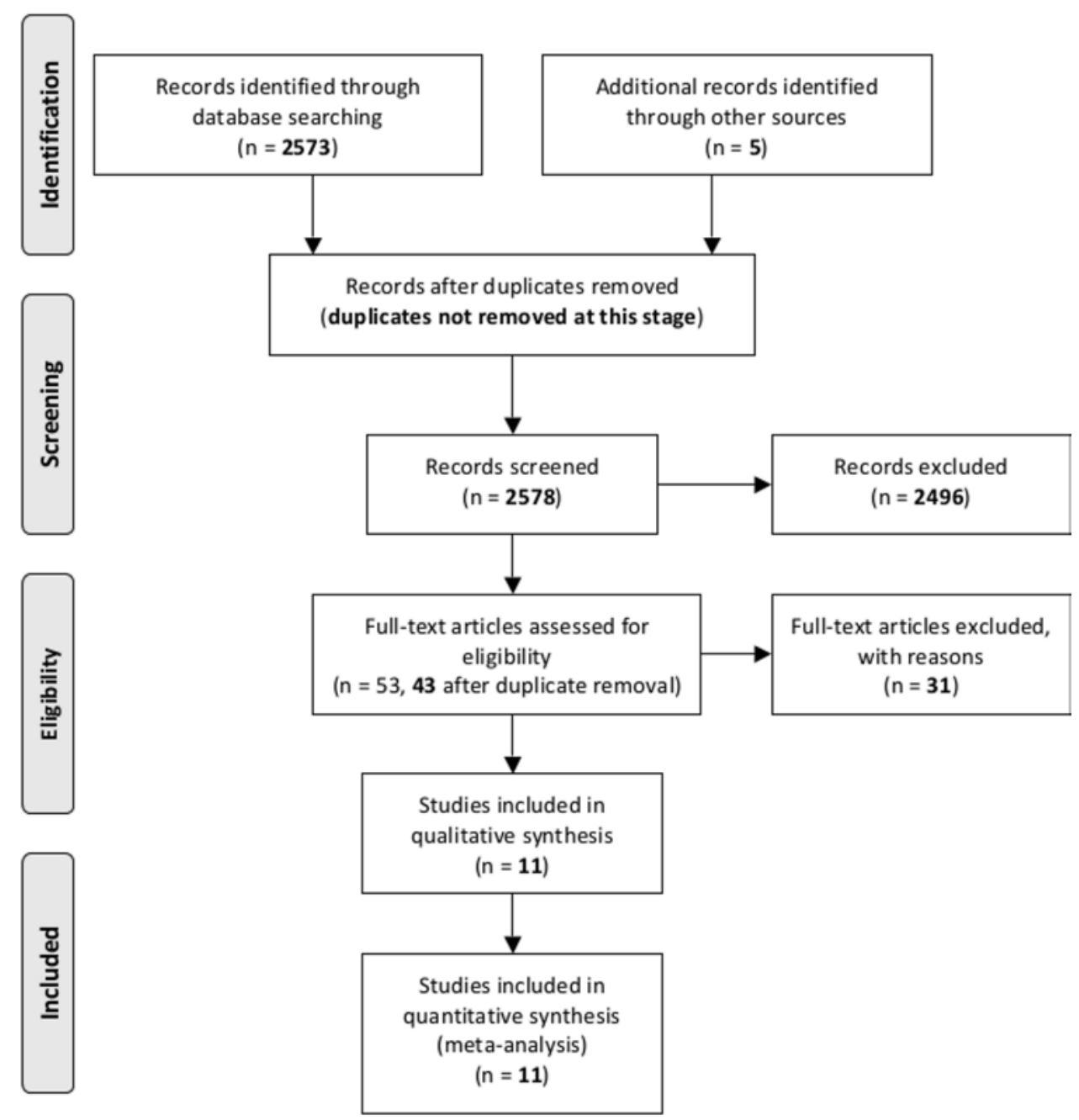

FIG. 1. PRISMA 2009 Flow Diagram of the literature search. From Moher D, Liberati A, Tetzlaff J, Altman DG: Preferred reporting items for systematic reviews and meta-analyses: the PRISMA statement. PLoS Med 6:e1000097, 2009. For more information, visit www.prisma-statement.org.

bias, after which these were excluded ${ }^{39}$ The pooled estimates (pooled odds ratio) were obtained using the MantelHaenszel fixed-effect method..$^{50} \mathrm{BAC}$ was dichotomized to negative and positive for the analyses.

\section{Role of the Funding Source}

The sponsor of the study had nothing to do with the design, analysis, interpretation, or writing of the study. The corresponding author had full access to the data, and had final responsibility for the decision to submit for publication.

\section{Results}

A total of 2578 titles issued between January 1, 1990, and October 7, 2013, were reviewed for relevance, from which 43 abstracts were chosen. From the chosen abstracts a total of 11 full-text articles were fully reviewed. ${ }^{1,3}$, 4,6,7,22,37,38,41,45,47 Individual study characteristics are shown in Table 1. All studies included were considered to be of high quality by the Newcastle-Ottawa quality assessment scale (Table 2). Three studies included only patients with severe TBI; 7 studies included patients with both blunt and penetrating TBI, and 6 studies considered patients with both isolated and polytrauma TBI. All studies reported incidence of in-hospital mortality with the exception of the studies by Alexander et al. ${ }^{1}$ (3-month mortality) and Chamoun et al. ${ }^{6}$ (death before 6 months). In the majority of the studies BAC was not obtained from all patients, and patients with missing BAC were excluded. One study ${ }^{41}$ used multiple imputations to replace missing BAC values. Seven of the 11 included studies had dichotomized BAC to positive and negative. Four studies ${ }^{1,3,41,47}$ had further categorized patients with positive BAC into low and high concentration levels (Table 1). Patients from these 4 studies were dichotomized into either BAC positive or negative for the primary analysis.

The final material for the primary analysis consisted of a total of 95,941 patients; 40,372 (42\%) were BAC-positive and 55,569 (58\%) were BAC-negative patients with moderate to severe TBI. Overall hospital mortality was $11.8 \%$, and the absolute difference between BAC-positive and 


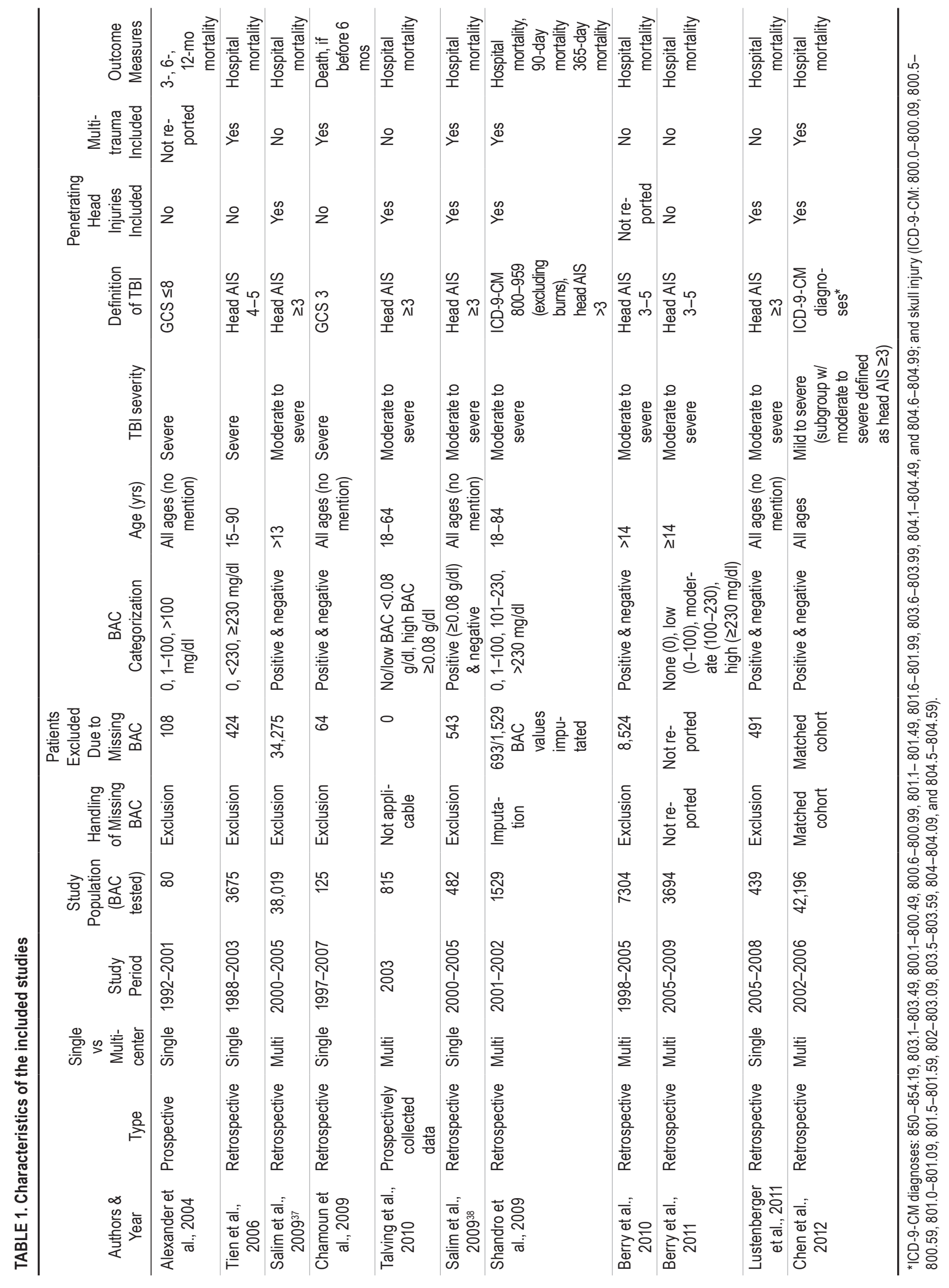


TABLE 2. Quality measure of included studies by the Newcastle-Ottawa quality assessment scale

\begin{tabular}{lcccc}
\hline \multicolumn{1}{c}{ Study } & Selection (max 4 stars) & Comparability (max 2 stars) & Outcome (max 3 stars) & Total Stars (max 9 stars) \\
\hline Alexander et al., 2004 & 4 & 1 & 3 & 8 \\
\hline Tien et al., 2006 & 4 & 1 & 3 & 8 \\
\hline Salim et al., 200937 & 4 & 1 & 3 & 8 \\
\hline Chamoun et al., 2009 & 4 & 1 & 3 & 7 \\
\hline Talving et al., 2010 & 4 & (no \& low together) & 3 & 8 \\
\hline Salim et al., 200938 & 4 & 1 & 3 & 7 \\
\hline Shandro et al., 2009 & 3 (multiple imputation) & 1 & 3 & 8 \\
\hline Berry et al., 2010 & 4 & 1 & 3 & 8 \\
\hline Berry et al., 2011 & 4 & 1 & 3 & 8 \\
\hline Lustenberger et al., 2011 & 4 & 1 & 3 & 8 \\
\hline Chen et al., 2012 & 4 & 1 & & \\
\hline
\end{tabular}

* Values are presented as stars. Studies with a total star count $\geq 6$ are considered high quality.

BAC-negative patients was $1.3 \%$ (overall mortality: BAC positive $11.0 \%$ vs BAC negative $12.3 \%$ ).

Primary analysis (11 studies, 95,941 patients) found the BAC-positive group to have a reduced risk of hospital mortality compared with the BAC-negative group (pooled OR 0.84 [95\% CI 0.81-0.88]). However, the primary analysis suffered from major study heterogeneity $\left(\chi^{2}=31.59\right.$, $\mathrm{p}$ $=0.0005, \mathrm{I}^{2}=68 \%$ ). A funnel plot diagram of the primary analysis is shown in Fig. 2.

To deal with this problem, multiple sensitivity analyses omitting one study at the time were conducted to identify studies causing heterogeneity. The highest heterogeneity was noted between the studies by Chen et al. ${ }^{7}$ and Salim et al. ${ }^{37}$ with an interstudy $\mathrm{I}^{2}$ of $88 \%\left(\chi^{2}=8.54, \mathrm{p}=0.003\right)$. Two other studies that notably increased the heterogeneity were those by Talving et al. ${ }^{45}$ and Tien et al. ${ }^{47}$ These studies were excluded from the sensitivity analyses. In the first sensitivity analysis the studies by Talving et al., ${ }^{45}$ Tien et al., ${ }^{47}$ and Salim et al. ${ }^{37}$ were excluded, resulting in a total of 55,949 patients, with an overall crude hospital mortality rate of $13.2 \%$ (BAC positive $12.2 \%$ vs BAC negative $14.0 \%)$. The pooled odds ratio was 0.87 (95\% CI $0.83-$ $0.92)$, with good study homogeneity $\left(\chi^{2}=10.97, \mathrm{p}=0.14\right.$, $\mathrm{I}^{2}=36 \%$ ). In the second sensitivity analysis Chen et al., instead of Salim et al. ${ }^{37}$ was omitted, resulting in a total of 51,771 patients, with a crude mortality rate of $9.9 \%$ (BAC positive $8.7 \%$ vs BAC negative $10.7 \%$ ). Pooled odds ratio was 0.78 (95\% CI 0.74-0.83) with good study homogeneity $\left(\chi^{2}=8.11, \mathrm{p}=0.32, \mathrm{I}^{2}=14 \%\right)$.

The primary, first and second sensitivity analyses are shown in Fig. 3.

Furthermore, as $81.4 \%$ of all patients came from 2 studies (Salim et al. ${ }^{37}$ and Chen et al. ${ }^{7}$ ), the pooled OR was also calculated using the Mantel-Haenszel random-effect method to balance out the study populations. Using the random-effect method the pooled OR was 0.82 (95\% CI 74-0.92), with similar heterogeneity to the primary analysis $\left(\chi^{2}=31.59, \mathrm{p}<0.001, \mathrm{I}^{2}=68 \%\right)$.

Post hoc power analysis of the primary analysis showed a $220 \%$ sample size to detect the $1.3 \%$ difference in mortality between BAC-positive and -negative patients, with a Type I error of 0.01 and $95 \%$ power. Likewise, the sen- sitivity analyses were largely overpowered to detect the $1.8 \%$ and $2.0 \%$ mortality differences for the first (224\%) and second sensitivity (332\%) analyses, respectively.

\section{Discussion}

\section{Key Findings}

We performed a meta-analysis of observational studies investigating the effect of BAC on hospital mortality in patients with moderate to severe TBI. Initially in the primary analysis we found positive BAC to be associated with decreased risk of death, although this initial analysis was confounded by major study heterogeneity. After sensitivity analysis and exclusion of the studies attributing to heterogeneity, the BAC-positive patient group remained the group having a significantly reduced risk of death compared with the BAC-negative control group.

Several studies have found positive BAC to be an independent predictor of survival after TBI after baseline risk adjustment (low BAC), 3,4,22, 37,38,45,47 while some studies have found no effect, ${ }^{1,6,7,41}$ or even an increased mortality (high BAC) ${ }^{47}$ Most included studies are register-based and thus are restricted to a limited repertoire of variables

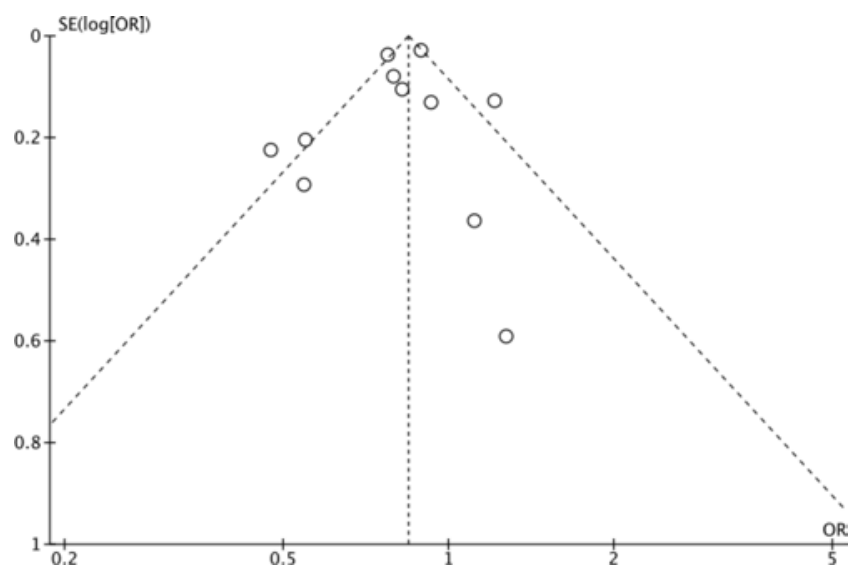

FIG. 2. Funnel plot diagram of the primary analysis showing relatively symmetrical distribution indicating no major study bias. 


\begin{tabular}{|c|c|c|c|c|c|c|c|c|}
\hline \multirow[b]{2}{*}{ Study or Subgroup } & \multicolumn{2}{|c|}{ BAC positive } & \multicolumn{2}{|c|}{ BAC negative } & \multirow[b]{2}{*}{ Weight } & \multirow{2}{*}{$\begin{array}{c}\text { Odds Ratio } \\
\text { M-H, Fixed, 95\% Cl }\end{array}$} & \multirow{2}{*}{\multicolumn{2}{|c|}{$\begin{array}{c}\text { Odds Ratio } \\
\text { M-H, Fixed, } 95 \% \mathrm{Cl}\end{array}$}} \\
\hline & Events & Total & Events & Total & & & & \\
\hline Alexander 2004 & 7 & 36 & 7 & 44 & $0.1 \%$ & $1.28[0.40,4.05]$ & & \\
\hline Berry 2010 & 274 & 3219 & 429 & 4085 & $6.8 \%$ & $0.79[0.68,0.93]$ & & \\
\hline Berry 2011 & 248 & 2451 & 161 & 1343 & $3.7 \%$ & $0.83[0.67,1.02]$ & & \\
\hline Chamoun 2009 & 25 & 54 & 31 & 71 & $0.3 \%$ & $1.11[0.55,2.27]$ & & \\
\hline Chen 2012 & 2299 & 18173 & 3351 & 24023 & $49.8 \%$ & $0.89[0.84,0.95]$ & 들 & \\
\hline Lustenberger 2011 & 20 & 204 & 39 & 235 & $0.6 \%$ & $0.55[0.31,0.97]$ & & \\
\hline Salim $2009^{37}$ & 1110 & 14419 & 2289 & 23600 & $31.6 \%$ & $0.78[0.72,0.84]$ & & \\
\hline Salim $2009^{38}$ & 48 & 179 & 121 & 303 & $1.3 \%$ & $0.55[0.37,0.82]$ & & \\
\hline Shandro 2009 & 110 & 550 & 207 & 979 & $2.4 \%$ & $0.93[0.72,1.21]$ & & \\
\hline Talving 2010 & 31 & 347 & 80 & 468 & $1.2 \%$ & $0.48[0.31,0.74]$ & & \\
\hline Tien 2006 & 269 & 740 & 134 & 418 & $2.2 \%$ & $1.21[0.94,1.56]$ & & \\
\hline Total $(95 \% \mathrm{Cl})$ & & 40372 & & 55569 & $100.0 \%$ & $0.84[0.81,0.88]$ & $\diamond$ & \\
\hline \multirow{2}{*}{\multicolumn{7}{|c|}{$\begin{array}{l}\text { Heterogeneity: } \text { Chi }^{2}=31.59, \mathrm{df}=10(P=0.0005) ; I^{2}=68 \% \\
\text { Test for overall effect: } Z=8.13(P<0.00001)\end{array}$}} & & \\
\hline & & & & & & & $\begin{array}{cc}0.5 & 0.7 \\
\text { Mortality [BAC } & 1\end{array}$ & $\begin{array}{lll}1.5 & 2 \\
\text { Mortality [BAC neqative] }\end{array}$ \\
\hline \multirow[b]{2}{*}{ Study or Subgroup } & \multicolumn{2}{|c|}{ BAC positive } & \multicolumn{2}{|c|}{ BAC negative } & & Odds Ratio & \multirow{2}{*}{\multicolumn{2}{|c|}{$\begin{array}{c}\text { Odds Ratio } \\
\text { M-H, Fixed, } 95 \% \mathrm{Cl}\end{array}$}} \\
\hline & Events & Total & Events & Total & Weight & M-H, Fixed, $95 \% \mathrm{Cl}$ & & \\
\hline Alexander 2004 & 7 & 36 & 7 & 44 & $0.2 \%$ & $1.28[0.40,4.05]$ & \multirow{3}{*}{$\rightarrow$} & \\
\hline Berry 2010 & 274 & 3219 & 429 & 4085 & $10.5 \%$ & $0.79[0.68,0.93]$ & & \\
\hline Berry 2011 & 248 & 2451 & 161 & 1343 & $5.7 \%$ & $0.83[0.67,1.02]$ & & \\
\hline Chamoun 2009 & 25 & 54 & 31 & 71 & $0.4 \%$ & $1.11[0.55,2.27]$ & & \\
\hline Chen 2012 & 2299 & 18173 & 3351 & 24023 & $76.6 \%$ & $0.89[0.84,0.95]$ & & \\
\hline Lustenberger 2011 & 20 & 204 & 39 & 235 & $1.0 \%$ & $0.55[0.31,0.97]$ & & \\
\hline Salim $2009^{38}$ & 48 & 179 & 121 & 303 & $2.0 \%$ & $0.55[0.37,0.82]$ & & \\
\hline Shandro 2009 & 110 & 550 & 207 & 979 & $3.6 \%$ & $0.93[0.72,1.21]$ & & - \\
\hline \multicolumn{2}{|l|}{ Total $(95 \% \mathrm{Cl})$} & 24866 & \multirow{2}{*}{\multicolumn{2}{|c|}{$4346^{31083}$}} & $100.0 \%$ & \multirow[t]{2}{*}{$0.87[0.83,0.92]$} & $\boldsymbol{\gamma}$ & \\
\hline \multicolumn{2}{|c|}{ Total events $\quad 3031$} & & & & & & & \\
\hline \multicolumn{7}{|c|}{$\begin{array}{l}\text { Heterogeneity: } \mathrm{Chi}^{2}=10.97, \mathrm{df}=7(P=0.14) ; I^{2}=36 \% \\
\text { Test for overall effect: } Z=5.36(P<0.00001)\end{array}$} & $\begin{array}{ccc}0.5 & 0.7 & 1 \\
\text { Mortality [BAC positive] }\end{array}$ & 1.52 \\
\hline \multirow[b]{2}{*}{ Study or Subgroup } & \multicolumn{2}{|c|}{ BAC positive } & \multicolumn{2}{|c|}{ BAC negative } & & Odds Ratio & \multirow{2}{*}{\multicolumn{2}{|c|}{$\begin{array}{c}\text { Odds Ratio } \\
\text { M-H, Fixed, } 95 \% \mathrm{Cl}\end{array}$}} \\
\hline & Events & Total & Events & Total & Weight & $\mathrm{M}-\mathrm{H}$, Fixed, $95 \% \mathrm{Cl}$ & & \\
\hline Alexander 2004 & 7 & 36 & 7 & 44 & $0.2 \%$ & $1.28[0.40,4.05]$ & & \\
\hline Berry 2010 & 274 & 3219 & 429 & 4085 & $14.6 \%$ & $0.79[0.68,0.93]$ & & \\
\hline Berry 2011 & 248 & 2451 & 161 & 1343 & $7.9 \%$ & $0.83[0.67,1.02]$ & & \\
\hline Chamoun 2009 & 25 & 54 & 31 & 71 & $0.6 \%$ & $1.11[0.55,2.27]$ & & \\
\hline Lustenberger 2011 & 20 & 204 & 39 & 235 & $1.4 \%$ & $0.55[0.31,0.97]$ & & \\
\hline Salim $2009^{37}$ & 1110 & 14419 & 2289 & 23600 & $67.5 \%$ & $0.78[0.72,0.84]$ & & \\
\hline Salim $2009^{38}$ & 48 & 179 & 121 & 303 & $2.8 \%$ & $0.55[0.37,0.82]$ & & \\
\hline Shandro 2009 & 110 & 550 & 207 & 979 & $5.0 \%$ & $0.93[0.72,1.21]$ & & \\
\hline Total $(95 \% \mathrm{Cl})$ & & 21112 & & 30660 & $100.0 \%$ & $0.78[0.74,0.83]$ & $\boldsymbol{\nabla}$ & \\
\hline Total events & 1842 & & 3284 & & & & & \\
\hline $\begin{array}{l}\text { Heterogeneity: } \mathrm{Chi}^{2}= \\
\text { Test for overall effect }\end{array}$ & $\begin{array}{l}8.11, \mathrm{df} \\
\mathrm{Z}=7.79\end{array}$ & $\begin{array}{l}=7(P= \\
(P<0 .\end{array}$ & $\begin{array}{l}0.32) ; 1^{2} \\
00001)\end{array}$ & $=14 \%$ & & & $\begin{array}{cc}0.5 & 0.7 \\
\text { Mortality [BAC } & \text { positive] }\end{array}$ & $\begin{array}{ccc}1 & 1.5 & 2 \\
\text { Mortality [BA }\end{array}$ \\
\hline
\end{tabular}

FIG. 3. Pooled estimates (pooled odds ratio) for the primary (upper), first sensitivity (center), and second sensitivity (lower) analyses. The primary analysis showed highest study heterogeneity $\left(I^{2}=68 \%\right)$, which was reduced in the first $\left(1^{2}=36 \%\right)$ and secondary $\left(I^{2}=14 \%\right)$ sensitivity analysis. All analyses found a highly significant pooled OR under one, indicating a reduced risk of death for patients with positive BAC. M-H = Mantel-Haenszel.

for baseline risk adjustment, such as the Injury Severity Score, AIS, and GCS. ${ }^{2,46}$ Although the GCS score is a strong predictor of outcome in TBI, its use may be limited in alcohol-intoxicated patients as it has been shown that alcohol may decrease the GCS score. ${ }^{40}$ Adjusting for the GCS score may lead to outcome bias as patients with positive BAC may be classified as having a more severe TBI than they really have. Thus, lack of standardized data collection and inadequate baseline risk adjustment is a poten- tial source of bias when interpreting the results of previous studies. On the other hand, only 2 studies, ${ }^{1,6}$ which together composed $0.4 \%$ of the total study population, used the GCS score as the primary inclusion criteria, while the other studies mainly used the head AIS score. Head AIS score is based on head CT features and is not as sensitive as the GCS score to the level of consciousness-lowering effects of alcohol. However, although several studies found positive BAC to be an independent predictor of survival 
following baseline risk adjustment, the individual study results should be interpreted with caution. Future studies should aim to use more precise tools for baseline risk adjustment, such as the IMPACT (International Mission for Prognosis and Analysis in Clinical Trials in TBI) model. ${ }^{42}$

Furthermore, as nearly all studies were retrospective in nature and excluded patients with missing BAC, selection bias is a concern. The study by Shandro et al. ${ }^{41}$ was the only study that used a multiple imputation technique to replace missing BAC values. Accordingly, study heterogeneity was inevitable in this meta-analysis of observational studies. Dealing with study heterogeneity is a complicated matter with no definitive solution. ${ }^{39}$ We chose to deal with heterogeneity by using a fixed-effect method and omitting one study at a time to identify studies causing heterogeneity so these could be excluded for sensitivity analysis.

The 2 largest studies (those by Salim et al. ${ }^{37}$ and Chen et $\mathrm{al}^{7}{ }^{7}$ ) were also found to be the largest source of heterogeneity. Both of these studies used data from the National Trauma Data Bank for roughly the same time period (2000-2005 and 2002-2006, respectively). There are, however, several methodological differences between the studies; for example, Salim et al. ${ }^{37}$ excluded those subjects who were not measured for BAC, while Chen et al. ${ }^{7}$ used a matched-cohort technique to identify BAC-positive and -negative patients. Also, Salim et al. ${ }^{37}$ considered only isolated TBI while Chen et al. ${ }^{7}$ also included polytrauma patients. Although it has been shown that the prognostic effect of extracranial injuries in moderate to severe TBI may be marginal, such factors may increase study heterogeneity ${ }^{35,48}$ Moreover, to adjust for the fact that approximately $80 \%$ of the included patients came from 2 studies (Salim et al. ${ }^{37}$ and Chen et al. ${ }^{7}$ ), we performed a secondary analysis, using the Mantel-Haenszel random-effect method. The random-effect method confirmed our results, indicating increased survival for BAC-positive TBI patients.

Talving et al. ${ }^{45}$ and Tien et al. ${ }^{47}$ were found to notably increase heterogeneity. Explanations for the increased heterogeneity after including these studies may be due to the fact that they categorized BAC-positive patients into 3 or more categories and not only into BAC-positive and -negative patients as most other studies had done. Low levels of BAC have been thought of as neuroprotective but high BAC as neurotoxic. ${ }^{17}$ Thus, combining all BAC-positive patients into one group may be one cause of heterogeneity. Furthermore, the study by Talving et al..$^{45}$ was one of the 2 prospective studies included and the only study that measured BAC from all patients, while the study by Tien et al. ${ }^{47}$ used older retrospective patient material dating back to 1988 .

Chronic alcoholism is an independent negative predictor of survival and a possible risk factor for increased neurotoxicity after TBI. ${ }^{16}$ The only study accounting for chronic alcoholism was that by Chen et al., 7 which excluded such patients. Chronic abusers are more likely to have a positive $\mathrm{BAC}$ at trauma admission than nonabusers, which would suggest higher mortality rates in the BAC-positive group, although the contrary was found.

In both the primary analysis and multiple sensitivity analyses, we found positive BAC to be significantly associated with reduced risk of death. Whether this is due to selection and patient bias or due to the possible neuroprotec- tive effects of alcohol remains unknown. The large sample size (total $n=95,941$ ) naturally has a role in yielding statistically significant results. Nonetheless, the biological background of the potential neuroprotective effects of alcohol should be considered before interpreting our results. The neuroprotective properties of alcohol have largely been attributed to its NMDAR inhibitory effects..$^{14,17}$ However, all clinical trials investigating NMDAR antagonists in TBI and stroke have been unsuccessful..$^{14,30}$ It has been postulated that one of the main reasons why the NMDAR antagonists have failed are due to the tight time-window for neuroprotection after brain injury. ${ }^{11,15,21,53}$ Patients with positive BAC on injury overcome this dilemma by already having the NMDAR antagonist present prior to injury. Administration of NMDAR antagonists prior to TBI have been shown to prevent neuronal death, possibly explaining some of the positive effects of alcohol. ${ }^{14}$ However, after the initial period of NMDAR inhibited glutamate excitoxicity, the interplay between glutamate and NMDAR is believed to play a vital role for neuronal survival, limiting the neuroprotective effect of NMDAR antagonists (and probably alcohol) to the acute setting. ${ }^{14}$ Furthermore, blunting of the hyperadrenergic response after TBI is also believed to contribute to the neuroprotective effects of alcohol. ${ }^{11,21,53}$

\section{Future Implications}

Due to data variations, we were unable to investigate the effect of different levels of BAC on outcome. For future studies it would be desirable to distinguish the effect value of low, moderate, and high BAC separately. Furthermore, the effect of the history of chronic alcohol abuse should be taken into account. Up until now it has been considered unethical to conduct clinical trials administering ethanol to injured patients. We found a $1 \%-2 \%$ decrease in mortality for alcohol-intoxicated TBI patients. Although the decrease is rather small and our study does not offer any Class I evidence, few other agents for the treatment of TBI have shown a comparable improvement in survival. ${ }^{26}$ There is still need for further prospective observational studies on the effect of alcohol on long-term outcome (including neurological outcome) after TBI with proper baseline risk adjustment and patient selection. Following this, clinical studies, investigating the neuroprotective effects of alcohol administration in patients with TBI may be warranted.

\section{Limitations}

There are some weaknesses in our analysis. First, due to the nature of the studies included, patient bias is a concern. Second, we were limited to using hospital mortality as the primary end point, which may not be an appropriate outcome measure after TBI. ${ }^{18,31,34}$ However, a recent study found low BAC levels also to significantly decrease risk of 6-month mortality. ${ }^{36}$ Third, we could not assess the effect of different levels of BAC on outcome.

\section{Conclusions}

Positive BAC was significantly associated with lower mortality rates after moderate to severe TBI. Whether this is due to selection bias or neuroprotection, however, re- 
mains unknown. Future prospective studies adjusting for TBI heterogeneity is advocated to establish the potential favorable effects of alcohol on outcome after TBI.

\section{Acknowledgment}

The study was funded by grants from Finska Läkaresällskapet, the Maire Taponen Foundation.

\section{References}

1. Alexander S, Kerr ME, Yonas H, Marion DW: The effects of admission alcohol level on cerebral blood flow and outcomes after severe traumatic brain injury. J Neurotrauma 21:575583,2004

2. Baker SP, O'Neill B, Haddon W Jr, Long WB: The injury severity score: a method for describing patients with multiple injuries and evaluating emergency care. J Trauma 14:187196, 1974

3. Berry C, Ley EJ, Margulies DR, Mirocha J, Bukur M, Malinoski D, et al: Correlating the blood alcohol concentration with outcome after traumatic brain injury: too much is not a bad thing. Am Surg 77:1416-1419, 2011

4. Berry C, Salim A, Alban R, Mirocha J, Margulies DR, Ley EJ: Serum ethanol levels in patients with moderate to severe traumatic brain injury influence outcomes: a surprising finding. Am Surg 76:1067-1070, 2010

5. Biegon A, Fry PA, Paden CM, Alexandrovich A, Tsenter J, Shohami E: Dynamic changes in N-methyl-D-aspartate receptors after closed head injury in mice: Implications for treatment of neurological and cognitive deficits. Proc Natl Acad Sci U S A 101:5117-5122, 2004

6. Chamoun RB, Robertson CS, Gopinath SP: Outcome in patients with blunt head trauma and a Glasgow Coma Scale score of 3 at presentation. J Neurosurg 111:683-687, 2009

7. Chen CM, Yi HY, Yoon YH, Dong C: Alcohol use at time of injury and survival following traumatic brain injury: results from the National Trauma Data Bank. J Stud Alcohol Drugs 73:531-541, 2012

8. Clifton GL, Ziegler MG, Grossman RG: Circulating catecholamines and sympathetic activity after head injury. Neurosurgery 8:10-14, 1981

9. Coronado VG, McGuire LC, Sarmiento K, Bell J, Lionbarger MR, Jones CD, et al: Trends in Traumatic Brain Injury in the U.S. and the public health response: 1995-2009. J Safety Res 43:299-307, 2012

10. Faul M, Wald MM, Rutland-Brown W, Sullivent EE, Sattin RW: Using a cost-benefit analysis to estimate outcomes of a clinical treatment guideline: testing the Brain Trauma Foundation guidelines for the treatment of severe traumatic brain injury. J Trauma 63:1271-1278, 2007

11. Hamill RW, Woolf PD, McDonald JV, Lee LA, Kelly M: Catecholamines predict outcome in traumatic brain injury. Ann Neurol 21:438-443, 1987

12. Higgins JPT, Green S: Cochrane Handbook for Systematic Reviews of Interventions. Chichester, UK: Wiley, 2008

13. Higgins JPT, Thompson SG, Deeks JJ, Altman DG: Measuring inconsistency in meta-analyses. BMJ 327:557560,2003

14. Ikonomidou C, Stefovska V, Turski L: Neuronal death enhanced by N-methyl-D-aspartate antagonists. Proc Natl Acad Sci U S A 97:12885-12890, 2000

15. Ikonomidou C, Turski L: Why did NMDA receptor antagonists fail clinical trials for stroke and traumatic brain injury? Lancet Neurol 1:383-386, 2002

16. Jurkovich GJG, Rivara FPF, Gurney JGJ, Fligner C, Ries R, Mueller BAB, et al: The effect of acute alcohol intoxication and chronic alcohol abuse on outcome from trauma. JAMA 270:51-56, 1993
17. Kelly DF: Alcohol and head injury: an issue revisited. J Neurotrauma 12:883-890, 1995

18. Langlois JA, Rutland-Brown W, Wald MM: The epidemiology and impact of traumatic brain injury: a brief overview. J Head Trauma Rehabil 21:375-378, 2006

19. Lee JM, Zipfel GJ, Choi DW: The changing landscape of ischaemic brain injury mechanisms. Nature 399 (6738 Suppl):A7-A14, 1999

20. Liberati A, Altman DG, Tetzlaff J, Mulrow C, Gøtzsche PC, Ioannidis JPA, et al: The PRISMA statement for reporting systematic reviews and meta-analyses of studies that evaluate healthcare interventions: explanation and elaboration. BMJ 339:b2700, 2009

21. Luna GK, Maier RV, Sowder L, Copass MK, Oreskovich MR: The influence of ethanol intoxication on outcome of injured motorcyclists. J Trauma 24:695-700, 1984

22. Lustenberger T, Inaba K, Barmparas G, Talving P, Plurad D, Lam L, et al: Ethanol intoxication is associated with a lower incidence of admission coagulopathy in severe traumatic brain injury patients. J Neurotrauma 28:1699-1706, 2011

23. Maas AIR: Neuroprotective agents in traumatic brain injury. Expert Opin Investig Drugs 10:753-767, 2001

24. Maas AIR, Menon DK, Lingsma HF, Pineda JA, Sandel ME, Manley GT: Re-orientation of clinical research in traumatic brain injury: report of an international workshop on comparative effectiveness research. J Neurotrauma 29:32-46, 2012

25. Maas AIR, Murray GD, Roozenbeek B, Lingsma HF, Butcher I, McHugh GS, et al: Advancing care for traumatic brain injury: findings from the IMPACT studies and perspectives on future research. Lancet Neurol 12:1200-1210, 2013

26. Maas AIR, Roozenbeek B, Manley GT: Clinical trials in traumatic brain injury: past experience and current developments. Neurotherapeutics 7:115-126, 2010

27. Maas AIR, Stocchetti N, Bullock R: Moderate and severe traumatic brain injury in adults. Lancet Neurol 7:728-741, 2008

28. Menon DK, Schwab K, Wright DW, Maas AI: Position statement: definition of traumatic brain injury. Arch Phys Med Rehabil 91:1637-1640, 2010

29. Molina PE, Sulzer JK, Whitaker AM: Alcohol abuse and the injured host: dysregulation of counterregulatory mechanisms review. Shock 39:240-249, 2013

30. Muir KW: Glutamate-based therapeutic approaches: clinical trials with NMDA antagonists. Curr Opin Pharmacol 6:53-60, 2006

31. Myburgh JA, Cooper DJ, Finfer SR, Venkatesh B, Jones D, Higgins A, et al: Epidemiology and 12-month outcomes from traumatic brain injury in Australia and New Zealand. J Trauma 64:854-862, 2008

32. Olesen J, Gustavsson A, Svensson M, Wittchen HU, Jönsson B: The economic cost of brain disorders in Europe. Eur J Neurol 19:155-162, 2012

33. Opreanu RC, Kuhn D, Basson MD: Influence of alcohol on mortality in traumatic brain injury. J Am Coll Surg 210:997-1007, 2010

34. Raj R, Bendel S, Reinikainen M, Kivisaari R, Siironen J, Lång M, et al: Hyperoxemia and long-term outcome after traumatic brain injury. Crit Care 17:R177, 2013

35. Raj R, Siironen J, Kivisaari R, Hernesniemi J, Tanskanen $\mathrm{P}$, Handolin L, et al: External validation of the IMPACT model and the role of markers of coagulation. Neurosurgery 73:305-311, 2013

36. Raj R, Skrifvars MB, Kivisaari R, Hernesniemi J, Lappalainen J, Siironen J: Acute alcohol intoxication and long-term outcome in patients with traumatic brain injury. J Neurotrauma 32:95-100, 2015

37. Salim A, Ley EJ, Cryer HG, Margulies DR, Ramicone E, Tillou A: Positive serum ethanol level and mortality in moderate 
to severe traumatic brain injury. Arch Surg 144:865-871, 2009

38. Salim A, Teixeira P, Ley EJ, DuBose J, Inaba K, Margulies DR: Serum ethanol levels: predictor of survival after severe traumatic brain injury. J Trauma 67:697-703, 2009

39. Schroll JB, Moustgaard R, Gøtzsche PC: Dealing with substantial heterogeneity in Cochrane reviews. Cross-sectional study. BMC Med Res Methodol 11:22, 2011

40. Shahin H, Gopinath SP, Robertson CS: Influence of alcohol on early Glasgow Coma Scale in head-injured patients. J Trauma 69:1176-1181, 2010

41. Shandro JR, Rivara FP, Wang J, Jurkovich GJ, Nathens AB, MacKenzie EJ: Alcohol and risk of mortality in patients with traumatic brain injury. J Trauma 66:1584-1590, 2009

42. Steyerberg EW, Mushkudiani N, Perel P, Butcher I, Lu J, McHugh GS, et al: Predicting outcome after traumatic brain injury: development and international validation of prognostic scores based on admission characteristics. PLoS Med 5:e165, 2008

43. Stroup DF, Berlin JA, Morton SC, Olkin I, Williamson GD, Rennie D, et al: Meta-analysis of observational studies in epidemiology: a proposal for reporting. Meta-analysis Of Observational Studies in Epidemiology (MOOSE) group. JAMA 283:2008-2012 2000

44. Tagliaferri F, Compagnone C, Korsic M, Servadei F, Kraus J: A systematic review of brain injury epidemiology in Europe. Acta Neurochir (Wien) 148:255-268, 2006

45. Talving P, Plurad D, Barmparas G, Dubose J, Inaba K, Lam $\mathrm{L}$, et al: Isolated severe traumatic brain injuries: association of blood alcohol levels with the severity of injuries and outcomes. J Trauma 68:357-362, 2010

46. Teasdale G, Jennett B: Assessment of coma and impaired consciousness. A practical scale. Lancet 2:81-84, 1974

47. Tien HCN, Tremblay LN, Rizoli SB, Gelberg J, Chughtai T, Tikuisis P, et al.: Association between alcohol and mortality in patients with severe traumatic head injury. Arch Surg 141:1185-1192, 2006

48. van Leeuwen N, Lingsma HF, Perel P, Lecky F, Roozenbeek $\mathrm{B}, \mathrm{Lu} \mathrm{J}$, et al : Prognostic value of major extracranial injury in traumatic brain injury: an individual patient data metaanalysis in 39,274 patients. Neurosurgery 70:811-818, 2012

49. Vázquez-Barquero A, Vázquez-Barquero JL, Austin O, Pascual J, Gaite L, Herrera S: The epidemiology of head injury in Cantabria. Eur J Epidemiol 8:832-837, 1992

50. Wallenstein S, Wittes J: The power of the Mantel-Haenszel test for grouped failure time data. Biometrics 49:1077-1087, 1993

51. Wells G, Shea B, O'Connell D, Peterson J, Welch V, Losos M, Tugwell P: The Newcastle-Ottawa Scale (NOS) for assessing the quality of nonrandomised studies in meta-analyses.
Ottawa Hospital Research Institute. (http://www.ohri. ca/programs/clinical_epidemiology/oxford.asp) [Accessed October 1, 2015]

52. Woolf PD, Cox C, Kelly M, McDonald JV, Hamill RW: Alcohol intoxication blunts sympatho-adrenal activation following brain injury. Alcohol Clin Exp Res 14:205-209, 1990

53. Woolf PD, Cox C, McDonald JV, Kelly M, Nichols D, Hamill RW, et al: Effects of intoxication on the catecholamine response to multisystem injury. J Trauma 31:1271-1276, 1991

54. Zink BJ, Feustel PJ: Effects of ethanol on respiratory function in traumatic brain injury. J Neurosurg 82:822-828, 1995

55. Zink BJ, Schultz CH, Wang X, Mertz M, Stern SA, Betz AL: Effects of ethanol on brain lactate in experimental traumatic brain injury with hemorrhagic shock. Brain Res 837:1-7, 1999

56. Zink BJ, Walsh RF, Feustel PJ: Effects of ethanol in traumatic brain injury. J Neurotrauma 10:275-286, 1993

\section{Disclosure}

The authors report no conflict of interest concerning the materials or methods used in this study or the findings specified in this paper.

\section{Author Contributions}

Conception and design: Raj, Mikkonen, Skrifvars. Acquisition of data: Raj, Mikkonen. Analysis and interpretation of data: Raj, Mikkonen, Siironen, Lappalainen, Skrifvars. Drafting the article: Raj, Mikkonen, Lappalainen, Skrifvars. Critically revising the article: all authors. Reviewed submitted version of manuscript: all authors. Approved the final version of the manuscript on behalf of all authors: Raj. Statistical analysis: Raj, Mikkonen, Skrifvars. Administrative/technical/material support: Siironen, Hernesniemi, Skrifvars. Study supervision: Siironen, Hernesniemi, Skrifvars.

\section{Supplemental Information \\ Online-Only Content}

Supplemental material is available with the online version of the article.

MOOSE Checklist and Electronic Literature Search. http:// thejns.org/doi/suppl/10.3171/2015.4.JNS141746.

\section{Correspondence}

Rahul Raj, Department of Neurosurgery, Helsinki University Hospital, Topeliuksenkatu 5, PB-266, Helsinki, 00029 HUS, Finland. email: rahul.br.raj@icloud.com. 